\title{
Article
}

\section{Scenario Expression Method for Regional Geological Structures}

\author{
Handong $\mathrm{He}^{1}{ }^{1}$, Yanrong Liu ${ }^{1}$, Jing $\mathrm{Cui}^{1}$ and $\mathrm{Di} \mathrm{Hu}^{2, *}$ \\ 1 School of Resources and Environment, Anhui Agricultural University, Hefei 230036, China; \\ hehandong@ahau.edu.cn (H.H.); liuyanrong@stu.ahau.edu.cn (Y.L.); cuijing@stu.ahau.edu.cn (J.C.) \\ 2 Key Laboratory of Virtual Geographic Environment, Nanjing Normal University, Ministry of Education, \\ Nanjing 210023, China \\ * Correspondence: 09374@njnu.edu.cn; Tel.: +86-189-5161-5704
}

Citation: He, H.; Liu, Y.; Cui, J.; $\mathrm{Hu}, \mathrm{D}$. Scenario Expression Method for Regional Geological Structures. ISPRS Int. J. Geo-Inf. 2022, 11, 47. https://doi.org/10.3390/ ijgi11010047

Academic Editor: Wolfgang Kainz

Received: 25 October 2021

Accepted: 6 January 2022

Published: 10 January 2022

Publisher's Note: MDPI stays neutral with regard to jurisdictional claims in published maps and institutional affiliations.

Copyright: (C) 2022 by the authors. Licensee MDPI, Basel, Switzerland. This article is an open access article distributed under the terms and conditions of the Creative Commons Attribution (CC BY) license (https:// creativecommons.org/licenses/by/ $4.0 /)$.

\begin{abstract}
Knowing the GIS expression of geological phenomena is an important basis for the combination of geology and GIS. Regional geological structures include folds, faults, strata, rocks, and other typical geological phenomena and are the focus of geological GIS research. However, existing research on the GIS expression of regional geological structure focuses on the expression of the spatial and attribute characteristics of geological structures, and our knowledge of the expression of the semantic, relationship, and evolution processes of geological structures is not comprehensive. In this paper, a regional geological structure scene expression model with the semantic terms positional accuracy, geometric shape, relationship type, attribute type, and time-type attributes and operations is proposed. A regional geological structure scenario markup language (RGSSML) and a method for mapping it with graphics are designed to store and graphically express regional geological structure information. According to the geological time scale, a temporal reference coordinate system is defined to dynamically express the evolution of regional geological structures. Based on the dynamic division of the time dimension of regional geological structures, the expression method of "time dimension + space structure" for the regional geological structure evolution process is designed based on the temporal model. Finally, the feasibility and effectiveness of the regional geological structure scene expression method proposed in this paper is verified using the Ningzhen Mountain (Nanjing section) as an example. The research results show that the regional geological structure scene expression method designed in this paper has the following characteristics: (1) It can comprehensively express the spatial characteristics, attribute characteristics, semantics, relationships, and evolution processes of regional geological structures; (2) it can be used to realize formalized expression and unified storage of regional geological information; and (3) it can be used to realize dynamic expression of the regional geological structure evolution process. Moreover, it has significant advantages for the expression of regional geological structure semantics, relationships, and evolution processes. This study improves our knowledge of the GIS expression of regional geological structures and is expected to further promote the combination and development of geology and GIS.
\end{abstract}

Keywords: GIS expression; regional geological structure; scenario; spatio-temporal characteristics; spatio-temporal process

\section{Introduction}

With nearly 60 years of development, GIS has continuously enriched semantic information, relational information, and temporal information on the basis of spatial and attribute information expression. Its expression methods have gone through several different stages, such as "space + attribute", "semantic + space + attribute", and "time + space + attribute" [1-4]. The GIS expression method of "space + attribute" is mainly used to describe the spatial coordinates, geometrical morphologies, and attributes of geographical objects $[5,6]$. However, information on semantics, times, and attributes is stored in an attribute table, making it difficult to express the meaning and spatial-temporal regulations of geographical objects. Researchers built a GIS expression method for "semantic 
+ space + attribute" that integrated geographical objects, phenomena, and regulations based on GIS semantics. This method is mainly based on the spatial and semantic mapping expression $[7,8]$, the natural language expression of geographical objects $[9,10]$, and geographical concept analysis [11,12]. It has certain advantages in the representation of geographical objects and their semantics, but is less useful for the expression of the time and process of geographical phenomena [13,14]. The GIS expression method for "time + space + attribute" was put forward to accurately describe various spatial-temporal features and relationships, including object-oriented [15,16], event-oriented [17,18], and process-oriented spatial-temporal data organization and analysis methods $[19,20]$. This expression method has made some progress in the cadastral, forestry, marine, transportation, and military fields, etc. [21,22]. On the other hand, it does not excel in the expression of continuous spatial-temporal evolution processes and dynamic geographical models. It can be seen that while GIS expression methods have made good progress, comprehensive GIS expression methods such as "semantic + space + time + process" are still in the development stage. A geographic scene can be defined as a specific regional synthesis comprising both human and natural factors and their mutual relationships and interactions [23,24]. Constructing GIS expression methods for geographical scenes ("semantic + location + geometry + attribute + relationship + process") may be able to better support the expression of the spatial structure and evolution of geographical phenomena, and this is gradually becoming the focus and development direction of GIS expression method research $[25,26]$.

The use of the tectonic expression method in geology is relatively well established. Geological information such as definition, occurrence, form, attribute, contact relationship, combining form, geological time, and geological event is mostly expressed through geological natural language, geological maps, geological classical theory, and the geological industry's norms and standards [27-30]. Many conventional natural language descriptions (such as fold, fault, joint, planes, lineation, etc.) have been formed in tectonic geology. This expression method involves a summary of the regularity of a geological structure by geological experts in long-term development. A number of classical theories (continental drift [31], seafloor spreading [32], plate tectonics [33], geomechanics [34], etc.) have emerged to express the spatial structure and evolution of geological structures. In addition, geological industry organizations express geological structures by formulating a series of norms and standards for classification, naming, codes, legends, etc. [35].

The application of GIS in the field of geology has gradually expanded. The GIS expression method for geological structures has gone through several different stages, such as "space + attribute", "semantic + space + attribute", and "time + space + attribute" [36-38]. (1) The GIS expression method for "space + attribute" abstracts the form and relation of a geological structure and expresses its geometry, attributes, and relationships. It describes the spatial position and geometry of the geological structure itself. Thus, the three-dimensional expression of a geological structure can be realized [39,40]. This kind of method is relatively mature, and includes the wire frame model [41], surface model [42], element model [43], geometry entity model [44], boundary representation model [45], and hybrid Model [46]. However, it is difficult to establish the spatial relationship between geometric objects using this method. The expression method of "space (topology) + attribute" was proposed; this method can express some geometric features and topological relations of geological structures. However, its ability to express the geological meanings and relationships of geological structures (fold, fault, etc.) needs to be strengthened. (2) The GIS expression method of "semantic + space + attribute" for geological structures is used to establish the conceptual system and hierarchical relationship of folds, faults, and strata using the conceptual geological relationship. Researchers have proposed the use of automatic classification methods for geological structures, focusing on machine learning and deep learning languages [47-49]. It can be seen that the main advantage of this method lies in the expression of the geological structure concept, but this method is weak in terms of the description of the space-time relationship in geological structures. (3) The GIS expression method of "time + space + attribute" for geological structures is used to study the spatio-temporal char- 
acteristics and spatio-temporal processes of geological structures from the three aspects of spatio-temporal differentiation, evolution process, and interaction mechanism. Regarding the aspect of focusing on spatio-temporal differentiation, this method aims at describing spatio-temporal relations and organizes geographical spatio-temporal phenomena using the basic idea of object orientation [50,51]. Time, space, and attribute are equally important to each spatio-temporal object with regard to expressing the spatio-temporal distribution of geological structures. Regarding the aspect of focusing on the evolution process, the geological structure evolution process can be divided into several periods. The evolution process of a geological object or object set over time is defined as a process of generating and responding to events with multi-time granularity so as to express the evolution process of the geological structure over time $[52,53]$. In terms of the interaction mechanism, the temporal and spatial characteristics of regional strata are analyzed by stratigraphy. A set of rules for examining the topological relationship of the strata in time and space is established. These can be used to accurately judge the topological relationship of the strata in the geological map and express the relation between the geological structure in time and space $[54,55]$. It can be seen that most GIS expression methods for geological structures express the spatio-temporal process in layers and segments through time points and time periods, but as yet there is still no method to continuously express the spatio-temporal evolution process of geological structures in the time dimension.

Heterogeneous geological data semantic gaps, varied three-dimensional space data expression of geological structures, access to huge amounts of geological attribute data, knowledge of geological structure relationships, and knowledge of complex geological structure time and space processes have gradually appeared in the field of vision [56-58]. These problems are not only challenges faced by geologists, but are also aspects that GIS scholars should pay attention to in the field of geology. With the development of GIS, computer science, and cartography, the expression methods for regional geological structures have gradually changed from geology to GIS. At the same time, GIS expression is developing from the traditional expression of "location + geometry + attribute" to the expression of "semantic + location + geometry + relation + attribute + process". The question of how to link the geological expression of regional geological structures (definition, occurrence, form, attribute, combination form, age, event) with scene expression (semantic description, spatial location, geometric form, attribute characteristics, element relationship, evolution process) and develop a GIS expression method for regional geological structures based on scenes is an urgent problem that needs to be solved by geologists and GIS scholars $[59,60]$. Therefore, taking basic regional geological structures such as folds, faults, strata, and rock masses as the research object, the scene expression model, spatial structure expression method, and evolution process expression method based on regional geological structures are studied. This can not only reveal the spatial structure and evolution process of regional geological structures effectively, but also provide a scene expression method that can be used as a reference for GIS, provide a new method and technical means for geological GIS research and applications, and promote the combination and development of geology and GIS.

\section{Method}

\subsection{Expression Model}

\subsubsection{Regional Geological Structure Scene Representation Concept Model}

In this section, the geological expression of regional geological structures in terms of space, time, attribute, and evolution process is discussed. The geological expression (definition, occurrence, form, attribute, contact relation, combination form, age, event, etc.) and the scene expression (semantic description, spatial position, geometric form, attribute characteristic, element relation, evolution process) correspond, as shown in Figure 1. 


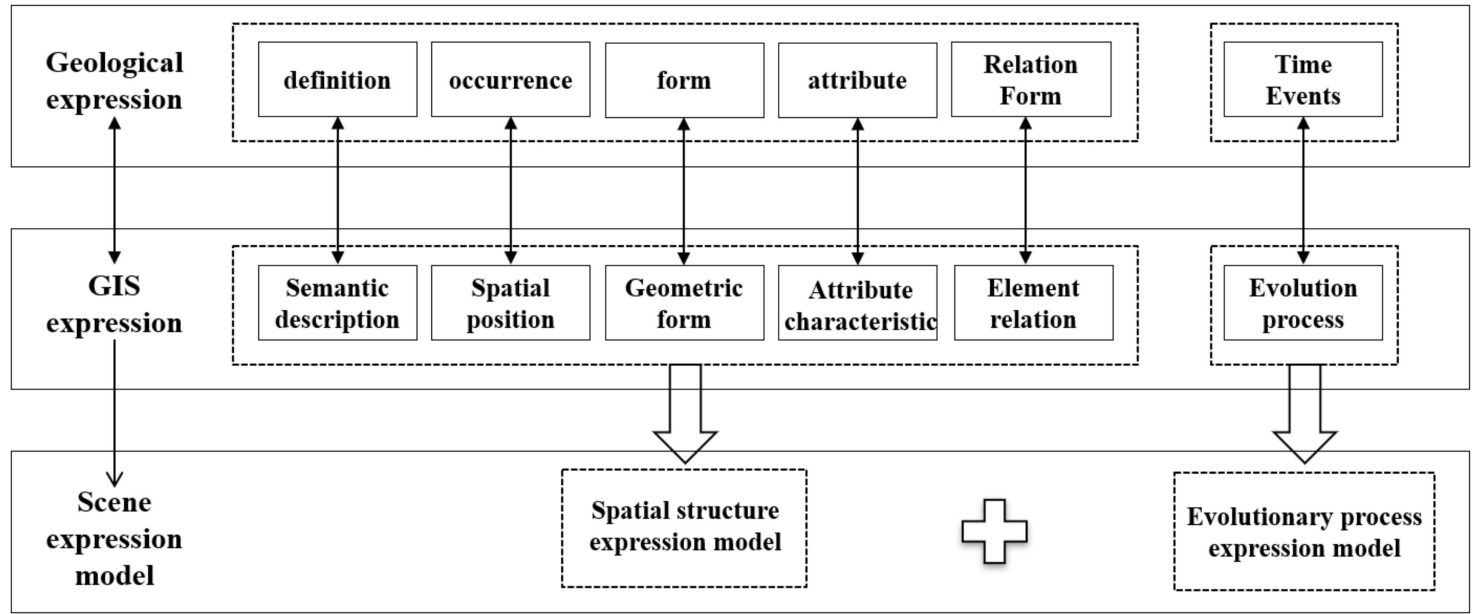

Figure 1. Correspondence between geological expression and GIS expression.

The corresponding relationship between the geological expression of regional geological structures and scene expression in this paper is as follows: Geological definition and GIS semantics; occurrence and GIS spatial location; form and GIS geometric form; geological attributes and GIS attributes; contact relations, combination forms, and GIS elements; geological time, geological events, and GIS time dimension; and evolution processes. The corresponding relationships between geology and GIS expression are shown in Table 1.

Table 1. Corresponding relationship between geology and the GIS expression of regional geological structures.

Geological Expression

Scene Expression

Geological definition: fold is the bending deformation of various rock surfaces by force

Semantic description: fold (A001), fold (A0011) ......

Occurrence: Starting from Chunhua in the west to Funiu Spatial location: Mountain in the east, the stratum strike is $115^{\circ}$

$\left(\mathrm{x}_{1}, \mathrm{y}_{1}, \mathrm{z}_{1}\right) \ldots \ldots\left(\mathrm{x}_{\mathrm{n}}, \mathrm{y}_{\mathrm{n}}, \mathrm{z}_{\mathrm{n}}\right)$

Form: the longitudinal section is $60 \mathrm{~km}$ long and $9 \mathrm{~km}$ wide... Geometric form: length, width ......

Geological attributes: sandstone, shale, metal elements, biological remains ...

GIS attributes: lithology, element, fossil, and other attribute data

Geological relations: unconformable contact relationships, translational fault systems ...

Element relations: topology relationship, association relationship ......

Geological time: relative age, absolute age,

Geological events, geological evolution process: process of the temporal and spatial variation of geological structure
Time dimension: initial, change, and extinction time points Evolution process: "Time dimension + Spatial structure"

\subsubsection{UML Design of Regional Geological Structure Scene Expression Model}

The scene expression model of regional geological structures shows an abstract generalization and expression of geological phenomena and fully expresses the spatial structure and evolution process of regional geological structures through semantic descriptions, spatial locations, geometric forms, attribute characteristics, element relations, evolution processes, and other elements. The UML design of this model is shown in Figure 2. 


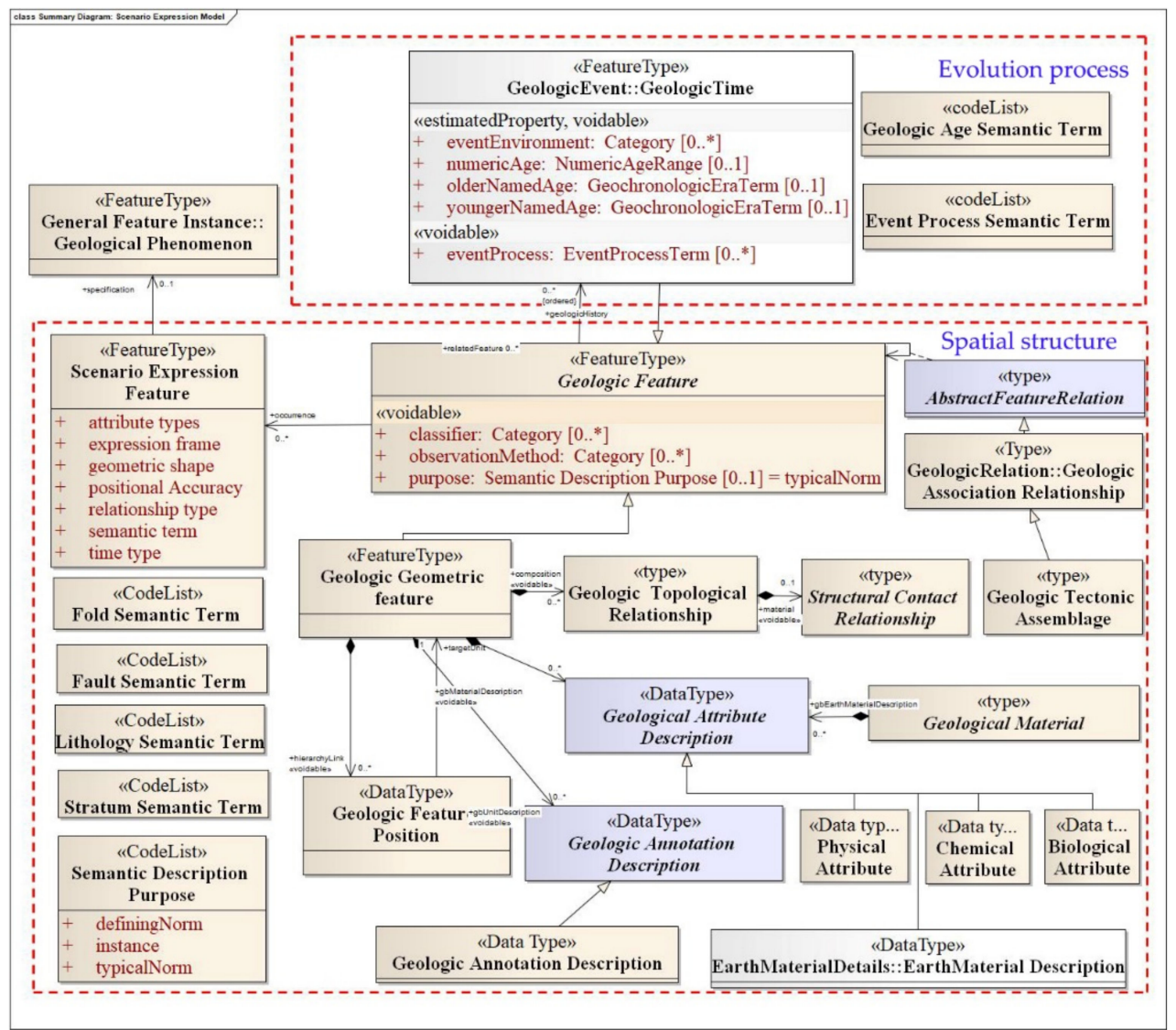

Figure 2. UML design of the regional geological structure scene expression model.

The scenario expression feature is based on the geologic features. It has a semantic term, as well as positional accuracy, geometric shape, relationship type, attribute types, and time type operation characteristics.

A. The semantic description is expressed by the fold semantic term, fault semantic term, stratum semantic term, lithology semantic term, and semantic description purpose. Its constructor is the code list.

B. The space location is expressed by the geologic feature position, which can be composed of spatial coordinates $(\mathrm{X}, \mathrm{Y}, \mathrm{Z})$, and its structural type is data type.

C. The geometric form is expressed by the geometric feature, which can be composed of geometric elements (point, line, polygon, etc.). The geometric elements are combinations of the location elements.

D. The attribute feature is expressed by the geological attribute description. It has four subclasses: physical attributes, chemical attributes, biological attributes, and Earth material descriptions.

E. The element relationship is expressed by the geologic association relationship and the geologic topological relationship. The geologic association relationship mainly expresses the non-spatial relation, such as the construction combination form, while the geologic topological relationship mainly expresses the spatial relationships, such as contact relation.

F. The evolution process is expressed by the geologic event: geologic time element. The operation features are the environment of the event, the younger named age, the numeric age, the older named age, and the event process. The geologic event: geologic time feature and geologic feature are implemented through inheritance. 


\subsection{Spatial Structure Expression}

Based on the XML markup language model, a regional geological structure scenario markup language (RGSSML) is proposed in this section. The method for the construction of semantic identification, coordinate parameter type, geometric symbol type, attribute type, and relationship type in spatial structures was realized by the object/relation pattern. The spatial structure storage was realized using the basic rules of mapping between RGSSML and object-relational databases. An RGSSML graphic representation of the spatial structure was realized through mathematical functions of the space set and range set of scene graphics and the mapping rules of graphic elements. Through geological rules, topological relations and association relations between scene objects can be expressed. These fully support the spatial structure extraction and expression of regional geological structures.

\subsubsection{The Construction Method of Spatial Structure}

We abstracted the spatial structures of regional geological structure as scene objects and their relations based on extensible markup language (XML). Thus, the spatial structure of regional geological structure was uniformly described and a method for the construction of regional geological structures was formed.

Based on XML, a RGSSML (regional geological structure scenario markup language) was designed. Based on the (object/relation) model, the construction of semantic identification, coordinate parameter type, geometric symbol type, attribute type, and relation type in the spatial structure of regional geological structure was realized. Specifically, these included the semantic schema, location schema, shape schema, attribute schema, and relation schema. Additionally, the coordinate reference system schema, time reference system schema, and temporal schema were introduced by including the element schema, as shown in Figure 3.

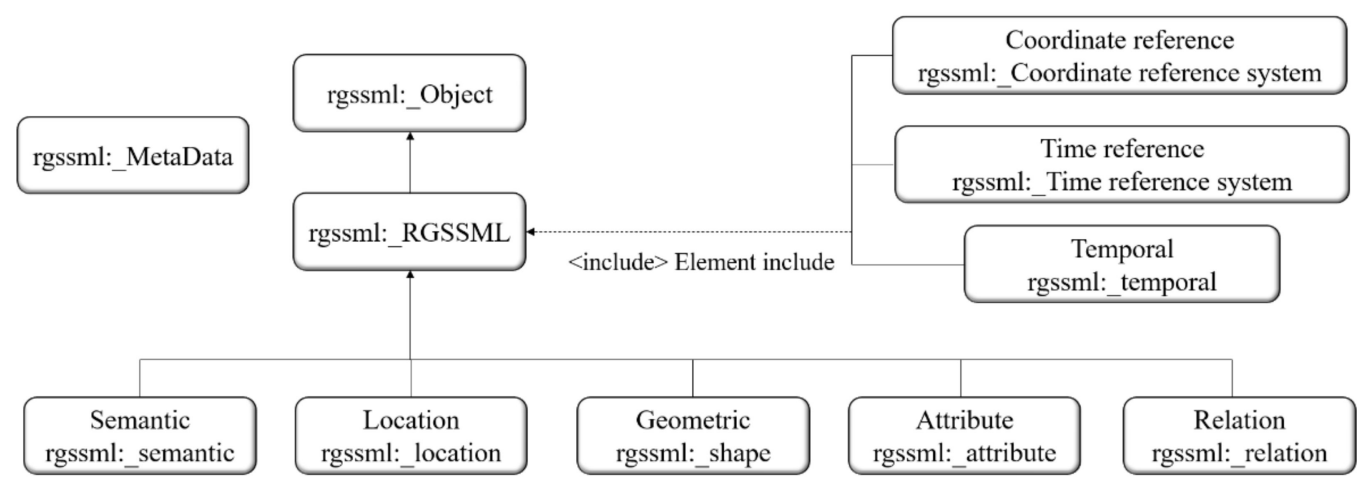

Figure 3. The method used for the construction of the scene.

\subsubsection{Storage of Spatial Structure}

The basic rules for mapping RGSSML to object-relational databases are summarized as follows:

1. Create corresponding tables in the object relational database for the different types of geological tectonic elements;

2. Create corresponding tables in an object-relational database for semantic objects, positional objects, and geometric objects, and create normative tables for semantic objects, positional objects, and geometric objects;

3. For simple types of geological structure element attributes, corresponding attribute columns already exist in the element table of the object relational database (step 1);

4. For geological structure element attributes of complex types, create a table for this complex type in the element table of the object relational database;

5. Create relational tables corresponding to complex elements and associate element tables with complex type tables through foreign keys; 
6. Create an association between elements and topology through topology-primitivevalue attributes, in which the topology primitives are linked using href.

\subsubsection{Graphic Representation of Spatial Structure}

RGSSML graphics are operated by RGSSML elements with domain and range sets. Scene graphics are defined as a mathematical function from the spatial set (function domain) to range set (function range). The distribution of aspect value sets (semantic coding values, spatial coordinate values, geometric elements, and attribute values) in spatial regions is described by constructing graphic-element mapping rules.

In Figure 4, the graph can be regarded as the graph of $f(x)$, as shown in (Equation (1)).

$$
\{(x, f(x)) \mid \operatorname{xin} A\}
$$
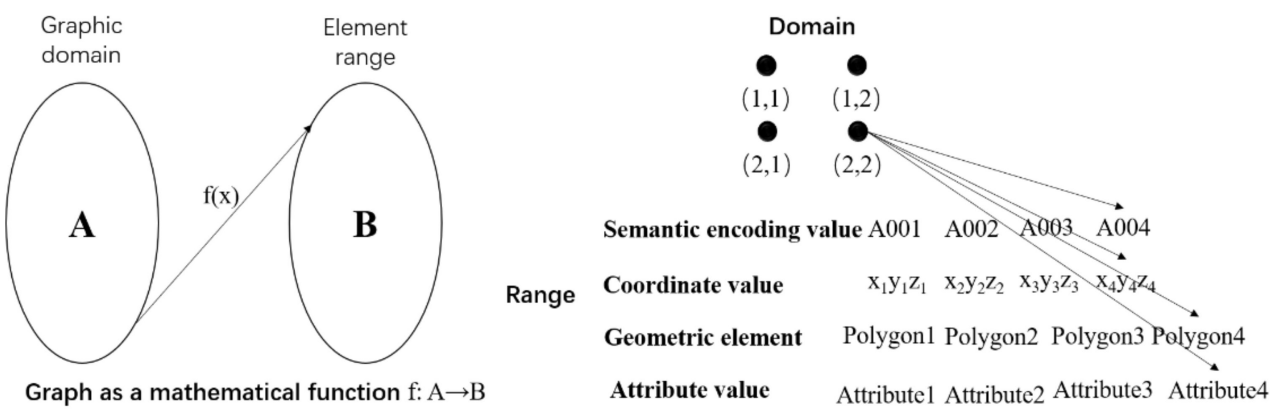

Figure 4. Graphic functions and mapping rules.

In an RGSSML instance, the value of a graph can be a string or an external reference to a specific mapping rule, and if the mapping rule is not specific the default mapping is linear. For example, the fourth figure in the definition domain corresponds to the fourth semantic encoding value, spatial coordinate value, geometric element, and attribute value in the range set.

The relation between geological objects can be divided into a topological relation and a correlation relation. The topological relation is used to express the geological relations with geometric significance, such as the fold core and fold, fold wing and fold, fold axial line, fault wall (hanging wall) and fault plane, fault wall (footwall) and fault plane, conformable contact, unconformable contact, intrusive contact, sedimentary contact, and fault contact. Correlation relation is used to express various interrelated geological relations under combination and order conditions, such as fold and fold, fold and stratum, fault and fold, fault and fault, and fault and stratum.

Regarding geological relations, not only do topological relations of spatial objects exist in geometric features, but also correlation relations exist between spatial objects that are independent of their own geometric features. This paper designs an association rule expression mechanism for correlation relations. These include anticlinorium, synclinorium, linear fold, brachy fold, dome, basin, longitudinal fault, transverse fault, oblique fault, graben, horst, reverse fault, strike-slip fault, strike fault, and dip fault.

\subsection{Evolutionary Process Expression}

In this section, the GIS time dimension is strengthened, time is introduced as a factor that is equally important to space, and a dynamic expression method for "time dimension + space structure" is proposed for the evolution of regional geological structures. A dynamic division method for regional geological structures at the initial time, change time, and end time is established. The definition and declaration of the temporal reference pattern and tense pattern are introduced into the spatial structure. The RGSSML time mode is defined by referring to the tense type defined in ISO19108, the time primitive in ISO8601, and the time interval in ISO11404. Referring to the geological time scale, the temporal 
spatial reference coordinate system is defined to dynamically express the evolution process of the regional geological structure. This can fully support the expression of the regional geological structure evolution process.

\subsubsection{Time Dimension Dynamic Partition Method}

The evolution process of regional geological structures is abstracted as the geological expression of "geological time + spatial structure". According to the geological time, the time sequence of regional geological structures in the process of evolution and development is established. At the same time, the geological identification and change analysis methods of regional geological structures for the definition, occurrence, form, attribute, contact relationship, and combination form in each geological period are established.

We strengthen the GIS time dimension and abstract geological time into the time dimension. A dynamic division method for regional geological structures at the initial time, change time, and end time of the time dimension is established. The dynamic changes in the geological structure evolution include the expression of tense semantics, tense locations, tense geometry, tense attributes, and tense relations. Regarding the GIS expression method of dynamic change, the design idea of this paper is that the spatial structure of regional geological structures is temporal and singular. Figure 5 shows the spatial-temporal evolution process of the linear structure phenomenon from time T1 to $\mathrm{T} 2$, which is represented by the dynamic change method, where " $\mathrm{T}$ " represents the time dimension and " $G$ " represents the space dimension. "Now" represents the current time and is a time variable whose valid value depends on the start time. The evolution of the linear structure phenomenon also needs to represent its change time and end time, as well as the temporal relation (TR) representation method is shown in Table 2.

Table 2. Dynamic expression of the geological structure evolution process.

\begin{tabular}{|c|c|c|}
\hline Serial Number & $\begin{array}{l}\text { T Time Dimensional } \\
\text { Representation }\end{array}$ & $\begin{array}{c}\text { TG Spatial-Temporal } \\
\text { Dimensional Representation }\end{array}$ \\
\hline 1 & T1 $(x 1, y 1$, t1-Now $)$ & TG1 (T1, T2, T3, T4, t1-t2) \\
\hline 2 & T2(x2, y2, t1-Now) & TG2 (T1, T2, T3, t1-Now) \\
\hline 3 & T3(x3, y3, t1-Now) & TG3 (T3, T4, t1-t2) \\
\hline 4 & $\mathrm{~T} 4(\mathrm{x} 4, \mathrm{y} 4, \mathrm{t} 1-\mathrm{t} 2)$ & TG4 (T4, T5, t2-Now) \\
\hline 5 & T5(x5, y5, t2-Now) & TG5 (T1, T2, T3, T4, T5, t2-Now) \\
\hline
\end{tabular}
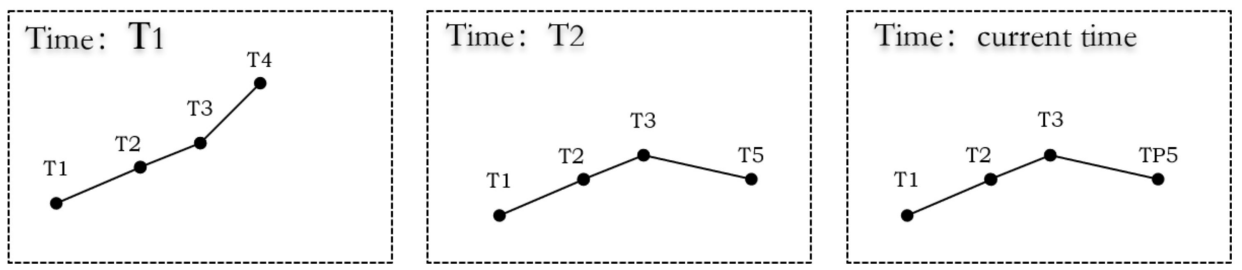

Figure 5. Geological structure spatial-temporal evolution process.

Temporal relation (TR) can be expressed by a $3 * 3$ matrix to compare the intersection of the front, inside, and back of two time periods. We assume that there are two time ranges, namely $\mathrm{TX}=[\mathrm{Xs}, \mathrm{Xe}]$ and $\mathrm{TY}=[\mathrm{Ys}, \mathrm{Ye}]$. Here, $\mathrm{X}-, \mathrm{XO}, \mathrm{X}+, \mathrm{Y}-, \mathrm{YO}$, and $\mathrm{Y}+$ indicate the front segment, inside segment, and back segment of TX and TY, respectively. The expression is $(\mathrm{X}-\cap \mathrm{Y}-, \mathrm{X}-\cap \mathrm{YO}, \mathrm{X}-\cap \mathrm{Y}+, \mathrm{XO} \cap \mathrm{Y}-, \mathrm{XO} \cap \mathrm{YO}, \mathrm{XO} \cap \mathrm{Y}+, \mathrm{X}+\cap \mathrm{Y}-, \mathrm{X}+\cap \mathrm{YO}$, $X+\cap Y+)$ and TR elements can be $\{0,1$ for empty set, non-empty set $\}$.

$$
\mathrm{TR}=\left(\begin{array}{ccc}
X-\cap Y- & X-\cap Y O & X-\cap Y+ \\
X O \cap Y- & X O \cap Y O & X O \cap Y+ \\
X+\cap Y- & X+\cap Y O & X+\cap Y+
\end{array}\right)
$$


2.3.2. The Expression of Evolution Process of Regional Geological Structure

The regional geological structure scenario markup language (RGSSML) proposed in this paper introduces definitions and declarations in a time reference system schema and temporal schema to a spatial structure through < include > element. RGSSML supports the modeling of dynamic spatial structures, which causes the spatial structure change with time. RGSSML refers to the temporal type defined in ISO19108 and adopts the time primions in ISO8601: TimeInstant and TimePeriod. Additionally, it adopts the time interval structure defined in ISO11404.

RGSSML, referring to "The International Commission on Stratigraphy" [61], intends to define a temporal reference coordinate system for dynamically expressing the evolution process of regional geological structures by referring to the geological time scale. Part of the geological time scale is shown in Table 3.

Table 3. Temporal reference coordinate system of the geological tectonic evolution (part).

\begin{tabular}{|c|c|c|c|c|}
\hline Eon & Era & Period & Epoch & Numerical Age (Ma) \\
\hline \multirow{14}{*}{ Phanerozoic } & \multirow{10}{*}{ Cenozoic } & \multirow{2}{*}{ Quaternary } & Holocene & Present-0.1 \\
\hline & & & Pleistocene & $0.1-2.58$ \\
\hline & & \multirow{7}{*}{ Neogene } & Pliocene & $2.58-5.33$ \\
\hline & & & $\ldots \ldots$ & $\ldots \ldots$ \\
\hline & & & $\cdots \cdots$ & $\cdots \cdots$ \\
\hline & & & $\ldots \ldots$ & $\ldots \ldots$ \\
\hline & & & $\ldots \ldots$ & $\ldots \ldots$ \\
\hline & & & $\ldots \ldots$ & $\ldots \ldots$ \\
\hline & & & $\ldots \ldots$ & $\ldots \ldots$ \\
\hline & & Palaeogene & $\ldots \ldots$ & $\ldots \ldots$ \\
\hline & \multirow{2}{*}{ Mesozoic } & Cretaceous & $\cdots \cdots$ & $\ldots \ldots$ \\
\hline & & $\cdots \cdots$ & $\cdots \cdots$ & $\cdots \cdots$ \\
\hline & \multirow{2}{*}{ Paleozoic } & Dyas & $\ldots \ldots$ & $\ldots \ldots$ \\
\hline & & $\ldots \ldots$ & $\ldots \ldots$ & $\ldots \ldots$ \\
\hline$\ldots \ldots$ & $\ldots \ldots$ & $\ldots \ldots$ & $\ldots \ldots$ & $\ldots \ldots$ \\
\hline
\end{tabular}

RGSSML proposes to define the TimeReferenceSystem and TimeEon, TimeEra, TimePeriod, and TimeEpoch structures of the temporal space reference coordinate system. Each component time period of the temporal spatial reference coordinate system is encapsulated with the $<$ Frame $>$ label. The following pseudo-code is used to formulate the dynamic expression of the regional geological structure evolution process in the period of $5.33 \mathrm{Ma}-2.58 \mathrm{Ma}-0.1 \mathrm{Ma}$ in Ningzhen Mountain range.

$<$ rgssml: TimeReferenceSystem rgssml:id="NanJing" $>$

$<$ rgssml: Frame $>$

$<$ rgssml: TimeEpoch rgssml:id="NanJing.NO.1" $>$ / / spatial structure NO.1

$<$ rgssml: description $>-10,000$ year $</$ rgssml: description $>$ / / Ma time $0.1 \mathrm{Ma}$

$</$ rgssml: TimeEpoch $>$

$</$ rgssml: Frame $>$

......

$<$ rgssml: TimeEpoch rgssml:id="NanJing.NO.3" $>$ / / spatial structure NO.3

$<$ rgssml: description $>-5,330,000$ year $</$ rgssml: description $>$ / / Ma time 5.33 Ma $\ldots \ldots$

$</$ rgssml: TimeReferenceSystem $>$ 


\section{Experiment}

In this paper, Ningzhen Mountain was selected as the research area to realize the scene expression of the regional geological structure. The main experimental data used were the natural language used by geologists to describe the geological structure phenomena in this region, the regional geology, a plane geological map, a geological history evolution table, and a stratigraphic code of the study area. These were combined with the Nanjing 1:10,000 DLG, the Nanjing 1:50,000 geographical base map, and the Ningzhen mountain 1:50,000 stratigraphic digital map. Our experiment was based on the object-relational database system. In this paper, definitions and declarations were introduced in the coordinate reference system schema, time reference system schema, and temporal schema. Through RGSSML's semantic schema, the location schema, shape schema, attribute schema, and relation schema were used to express the spatial structure characteristics and evolution process of the regional geological structure scenes.

Based on the regional range set of Ningzhen Mountain (Nanjing section), in this paper we constructed the graphic spatial structure feature expression. Figure $6 \mathrm{a}, \mathrm{b}$ graphically express the semantic, spatial location, geometric form, and attribute characteristics of Ningzhen Mountain (Nanjing section) from a map view and a 3D view, respectively.

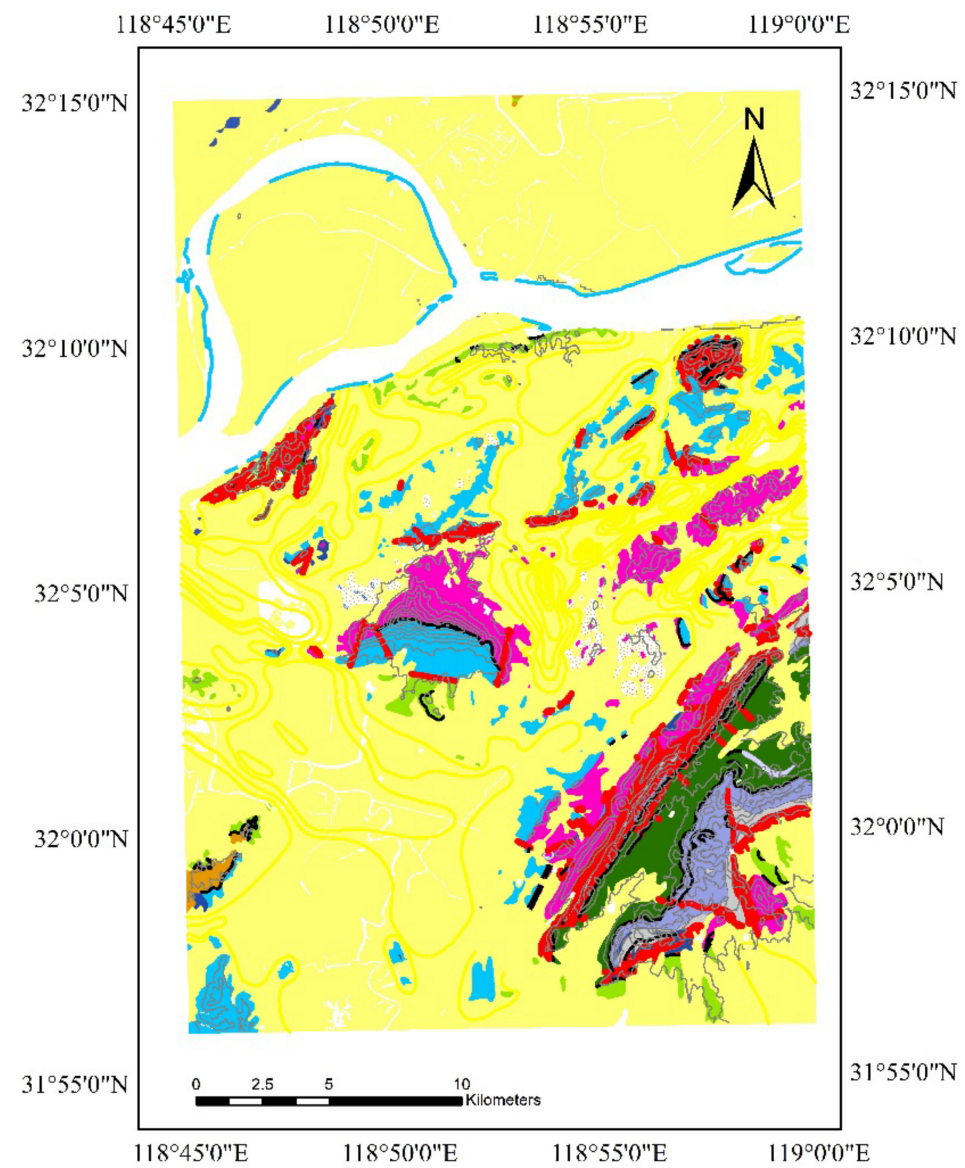

(a)

Figure 6. Cont. 


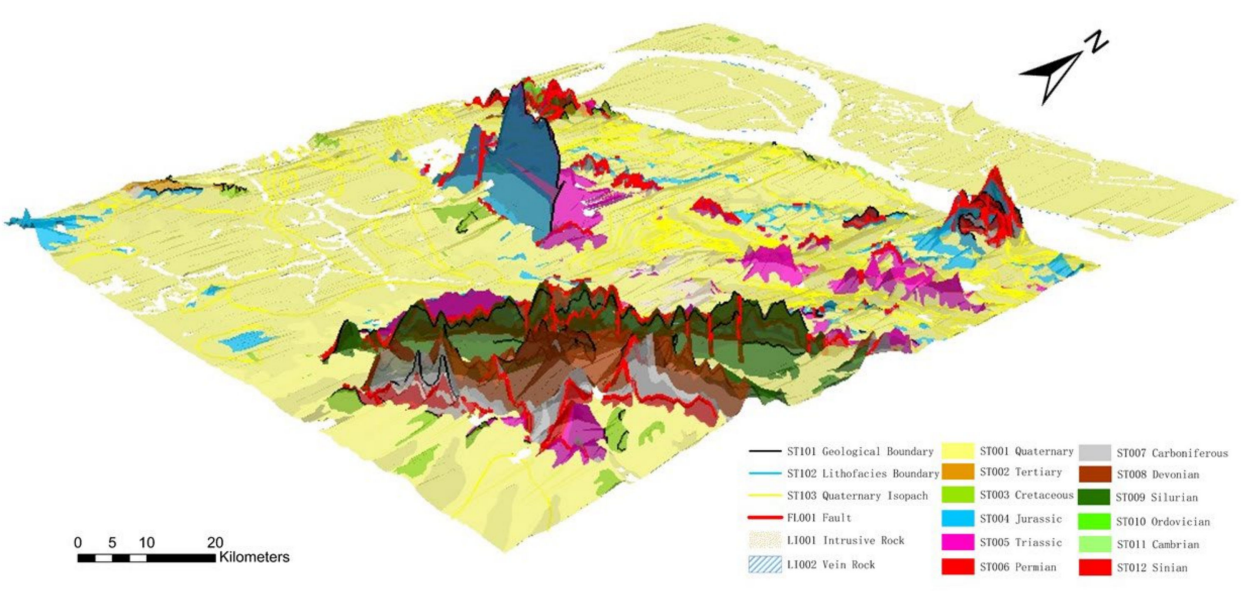

(b)

Figure 6. Graphic representation of the spatial structure RGSSML of the Ningzhen Mountain range (Nanjing section).

Semantic coding value: we used the ST001, ST002, ... . . . , FL001, ... LI002 code values expressed in the quaternary strata. We also used the tertiary strata, ... fault, ... $\ldots$ and semantic characteristics of dike rocks.

Space coordinate value: The coordinate value through point column $(x 1, y 1, z 1)$, $(x 2, y 2, z 2) \ldots$, and $(x n, y n, z n)$ express the coordinates of space objects.

Geometric elements: stratigraphic boundaries, lithofacies boundaries, quaternary isopachines, fault lines, quaternary strata, tertiary strata, and Sinian strata were used to express the geometry of space objects.

Attribute value: we used attribute fields to store the physical, chemical, and biological attributes of space objects, such as lithology, rock color, structure, structure, and fossil name.

The proposed temporal pattern supports the use of temporal semantics, temporal location, temporal geometry, and temporal attributes. Meanwhile, the temporal relation (TR) can be expressed by a $3 * 3$ matrix. This paper intends to use the dynamic semantic coding, dynamic location, dynamic geometry, dynamic attribute, and dynamic relation expression of the semantics, location, geometry, attribute, and relation to realize the expression of the regional geological structure evolution process. This paper intends to express the regional geological structure evolution process of 5.33 Ma-2.58 Ma-0.1 Ma in the Ningzhen Mountain (Nanjing section). Figure 7 reflects the semantic coding, geometric morphology, spatial location, and stratigraphic attributes of the Pliocene, Pleistocene, and Holocene at $5.33 \mathrm{Ma}$, and 2.58 Ma, and 0.1 Ma under different time epoch elements. Additionally, the stratigraphic contact relationship was expressed for geological ages of 5.33 Ma-2.58 Ma and 2.58 Ma-0.1 Ma. 


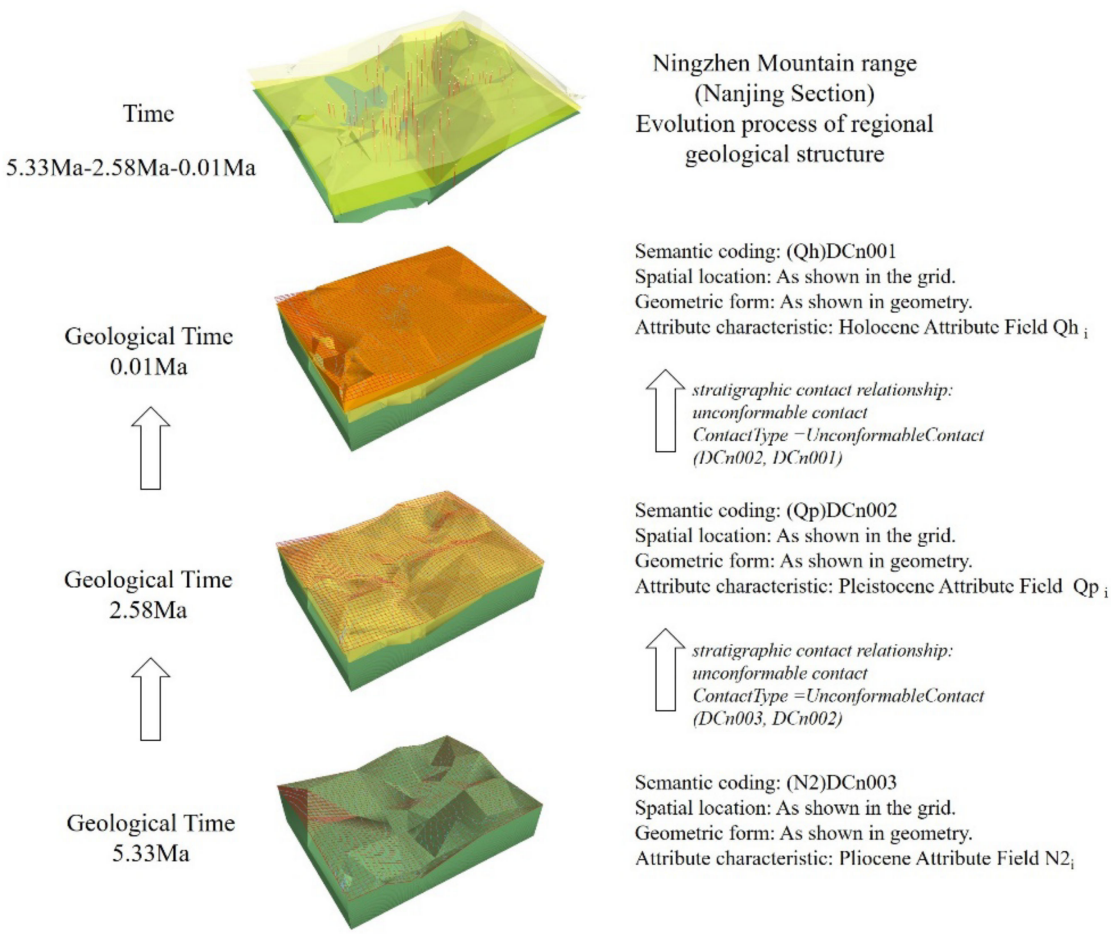

Figure 7. Evolution of the regional geological structure in the Ningzhen Mountain (Nanjing section).

\section{Conclusions}

In this paper, scenes (semantic description, spatial location, geometric form, attribute characteristics, element relations, evolution process) were introduced into GIS representations of regional geological structures. Based on the correspondence between the geological expression and scene expression of the regional geological structures, a scene expression model for regional geological structures was designed, a method for the expression of the regional geological structure spatial structure characteristics and evolution process was realized, and a scene expression method for regional geological structures was formed. (1) Based on the geological expression of the regional geological structure (definition, occurrence, form, attribute, contact relation, combination form, age, event, etc.), a scenario expression feature was proposed. In this paper, a scene expression model of regional geological structures with semantic terms, positional accuracy, geometric shape, relationship type, attribute types, time type, and operation was constructed. (2) Based on the XML markup language model, a regional geological structure scenario markup language (RGSSML) was proposed in this paper. The method used for the construction of semantic identification, coordinate parameter type, geometric symbol type, attribute type, and relationship type in spatial structures was realized by the object/relation pattern. The spatial structure storage was realized by the basic rules of mapping between RGSSML and object-relational databases. The RGSSML graphic representation of the spatial structure was realized through the mathematical functions of the space set and a range set of scene graphics and mapping rules of graphic elements. Through geological rules, topological relations and association relations between scene objects can be expressed. These can fully support the spatial structure extraction and the expression of regional geological structures. (3) According to the INTERNATIONAL CHRONOSTRATIGRAPHIC CHART, a chronological sequence of regional geological structures in the process of evolution and development was established. The geological time was abstracted into the time dimension, and the temporal reference model and temporal model were introduced into the spatial structure to support the modeling and expression of the dynamic spatial structure.

The regional geological structure scene expression method proposed in this paper had the following characteristics: (1) it could comprehensively express the spatial characteristics, 
attribute characteristics, semantics, relations, and evolution process of regional geological structures; (2) the formalized expression and unified storage of regional geological information were realized; (3) the dynamic expression of the regional geological structure evolution process was realized, bringing significant advantages in the expression of regional geological structure semantics, relations, and evolution processes. The method proposed in this paper can effectively reveal the spatial structure and evolution process of regional geological structures, provide a new method and technical means for the research and application of geological GIS, and promote the combination and development of geology and GIS.

Author Contributions: Handong He designed the research flow and wrote the manuscript. Yanrong Liu and Jing Cui performed the data analysis of the study. Di Hu contributed significantly to the conception of the study and the constructive discussion. All authors have read and agreed to the published version of the manuscript.

Funding: This work is supported by the National Natural Science Foundations of China (No. 42071365, 41771421). As well as by The National Undergraduate Innovation and Entrepreneurship Training Program (No. 201910364245).

Institutional Review Board Statement: No applicable.

Informed Consent Statement: No applicable.

Data Availability Statement: No applicable.

Acknowledgments: This work is supported by the National Natural Science Foundations of China (No. 42071365,41771421), as well as by The National Undergraduate Innovation and Entrepreneurship Training Program (No. 201910364245). We would like to express our sincere thanks to the anonymous reviewers and editors for their valuable comments and suggestions for this paper.

Conflicts of Interest: The authors declare that they have no conflict of interest.

\section{References}

1. Liyang, X.; Guoan, T.; Xin, Y.; Fayuan, L. Geomorphology-oriented digital terrain analysis: Progress and perspectives. J. Geogr. Sci. 2021, 31, 456-476.

2. Chen, X.X.; Liang, L.I.; Tan, L.; Yang, L. Study of urban greenway planning based on multi-source data analysis of spatial potential and user behaviors-The Greenway route planning of haidian district, Beijing. Landsc. Archit. Front. 2020, 7, 50-65. [CrossRef]

3. Breunig, M.; Bradley, P.E.; Jahn, M.; Kuper, P.; Jadidi, M. Geospatial Data Management Research: Progress and Future Directions. Int. J. Geo-Inf. 2020, 9, 95. [CrossRef]

4. Lü, G.; Batty, M.; Strobl, J.; Lin, H.; Chen, M. Reflections and speculations on the progress in Geographic Information Systems (GIS): A geographic perspective. Int. J. Geogr. Inf. Sci. 2018, 33, 346-367. [CrossRef]

5. Rahman, M.T.; Jamal, A.; Alahmadi, H.M. Examining Hotspots of Traffic Collisions and their Spatial Relationships with Land Use: A GIS-Based Geographically Weighted Regression Approach for Dammam, Saudi Arabia. Int. J. Geo-Inf. 2020, 9, 540. [CrossRef]

6. Chen, Q.; Chen, J.; Huang, W. Method for Generation of Indoor GIS Models Based on BIM Models to Support Adjacent Analysis of Indoor Spaces. Int. J. Geo-Inf. 2020, 9, 508. [CrossRef]

7. Ling, Z.; Fei, D. Integration Method of BIM and 3D GIS Based on Semantic Mapping. J. Geomat. 2016, 3, 16-19. (In Chinese)

8. Ye, X.; Du, J.; Gong, X.; Na, S.; Kudva, S. Geospatial and Semantic Mapping Platform for Massive COVID-19 Scientific Publication Search. J. Geovis. Spat. Anal. 2021, 5, 5. [CrossRef]

9. Zhang, C.; Zhang, X.; Chen, Y.; Yu, W. Extraction of Geographical Attribute-Values in Natural Language Text; Springer: Berlin/Heidelberg, Germany, 2012; Volume 142, pp. 51-59.

10. Tang, T.; Cao, Q.; Zhang, L.; Long, Y. Simulated Expression Method of Spatial Relationship of Natural Language of Point, Line and Object. J. Geo-Inf. Sci. 2018, 20, 139-146. (In Chinese)

11. Lanlan, L.; Yongsheng, L.; Tao, L.; Jinmei, Z.; Donghai, G. Analysis of Geographic Information Concept Based on Framework Semantic. Geospat. Inf. 2014, 1, 61-64. (In Chinese)

12. Yu, L.; Lin, L.; Shen, H.; Yang, H.; Feng, L. A Co-Citation and Cluster Analysis of Scientometrics of Geographic Information Ontology. Int. J. Geo-Inf. 2018, 7, 120.

13. Salvatore, P.; Robert, A. Addressing Semantic Geographic Information Systems. Future Internet 2013, 5, 585-590.

14. Lin, L.; Yu, L.; Zhu, H.; Shen, Y.; Hang, S. A bibliometric and visual analysis of global geo-ontology research. Comput. Geosci. $2017,99,1-8$.

15. Chee, Y.E.; Wilkinson, L.; Nicholson, A.E.; Quintana-Ascencio, P.F.; Fauth, J.E.; Hall, D.; Ponzio, K.J.; Rumpff, L. Modelling spatial and temporal changes with GIS and Spatial and Dynamic Bayesian Networks. Environ. Model. Softw. 2016, 82, 108-120. [CrossRef] 
16. Allen, M.J.; Allen, T.R.; Davis, C.; Mcleod, G. Exploring Spatial Patterns of Virginia Tornadoes Using Kernel Density and Space-Time Cube Analysis (1960-2019). Int. J. Geo-Inf. 2021, 10, 310. [CrossRef]

17. Lafrance, F.; Daniel, S.; Dragićević, S. Multidimensional Web GIS Approach for Citizen Participation on Urban Evolution. ISPRS Int. J. Geo-Inf. 2019, 8, 253. [CrossRef]

18. Silva, C.; Melo, S.; Santos, A.; Junior, P.A.; Sato, S.; Santiago, K.; Sá, L. Spatial Modeling for Homicide Rates Estimation in Pernambuco State-Brazil. ISPRS Int. J. Geo-Inf. 2020, 9, 740. [CrossRef]

19. Song, Y.; Niu, L. Combinatorial Spatial Data Model for Building Fire Simulation and Analysis. Int. J. Geo-Inf. 2019, 8, 408. [CrossRef]

20. Xie, Y.; Wang, M.; Liu, X.; Mao, B.; Wang, F. Integration of Multi-Camera Video Moving Objects and GIS. ISPRS Int. J. Geo-Inf. 2019, 8, 561. [CrossRef]

21. Zui, H.U.; Tang, G.; Guonian, L.U. A new geographical language: A perspective of GIS. J. Geogr. Sci. 2014, 24, 560-576.

22. Shyamantha, S.; Ronald, E.; Yuji, M. Spatiotemporal Analysis of Urban Growth Using GIS and Remote Sensing: A Case Study of the Colombo Metropolitan Area, Sri Lanka. Int. J. Geo-Inf. 2016, 5, 197.

23. Wenwen, L.; Xiran, Z.; Sheng, W. An Integrated Software Framework to Support Semantic Modeling and Reasoning of Spatiotemporal Change of Geographical Objects: A Use Case of Land Use and Land Cover Change Study. ISPRS Int. J. Geo-Inf. 2016, 5,179 .

24. Lü, G.; Chen, M.; Yuan, L.; Zhou, L.; Wen, Y.; Wu, M.; Hu, B.; Yu, Z.; Yue, S.; Sheng, Y. Geographic scenario: A possible foundation for further development of virtual geographic environments. Int. J. Digit. Earth 2017, 11, 356-358. [CrossRef]

25. Lv, G.; Yuan, L.; Yu, Z. Challenges to Development and Socialization of GIS Technology. J. Geo-Inf. Sci. 2013, 15, 483-490. [CrossRef]

26. Lv, G.; Zhao, Y.; Yuan, L.; Luo, W.; Wu, M.; Sheng, Y. Is the future of cartography the scenario scicence? J. Geo-Inf. 2018, 20 , 1-6.

27. Ho, V.L.; Dorrell, R.M.; Keevil, G.M.; Thomas, R.E.; Mccaffrey, W.D. Dynamics and Deposition of Sediment-Bearing Multi- Pulsed Flows and Geological Implication. J. Sediment. Res. 2019, 89, 1127-1139. [CrossRef]

28. Liang, J.; Zhang, W.; Lu, J.; Wei, J.; He, Y. Geological occurrence and accumulation mechanism of natural gas hydrates in the eastern Qiongdongnan Basin of the South China Sea: Insights from site GMGS5-W9-2018. Mar. Geol. 2019, 418, 106042. [CrossRef]

29. Layzell, A.L.; Mandel, R.D. Late Quaternary landscape evolution and bioclimatic change in the central Great Plains, USA. Geol. Soc. Am. Bull. 2020, 132, 11-12. [CrossRef]

30. Pavlun, M.M.; Generalova, L.V. A Significant Contribution to the Understanding of the Historical and Geological Formation of the Transcarpathian Depression Geotectonic Structure. Geol. J. 2019, 3, 78-85.

31. Stoneley, R. The Niger Delta Region in the Light of the Theory of Continental Drift. Geol. Mag. 1966, 103, 385-397. [CrossRef]

32. Gupta, A.; Scholz, C.H. Brittle strain regime transition in the Afar depression: Implications for fault growth and seafloor spreading. Geology 2000, 28, 1087-1090. [CrossRef]

33. Lewis, C.L.E. Arthur Holmes' unifying theory: From radioactivity to continental drift. Geol. Soc. Lond. Spec. Publ. 2002, 192, 167-183. [CrossRef]

34. Chen, J.; Jiang, Z.; Zhang, W.; Liu, C.; Han, C. The study on the modern sedimentary system of Buha River Delta in Qinghai Lake. Geol. J. 2019, 55, 5216-5232. [CrossRef]

35. Zhang, Z.W.; Ren, X.A.; Liu, X.D. Research on the construction of physical geological data's information organization and release. China Min. Mag. 2015, 24, 141-146.

36. Jordan, G.; Csillag, G.; Szucs, A.; Qvarfort, U.J.Z.f.G. Application of digital terrain modelling and GIS methods for the morphotectonic investigation of the Kali Basin, Hungary. Z. Geomorphol. 2003, 47, 145-169. [CrossRef]

37. Abuelnaga, H.; Aboud, E.; Harbi, H.M.; Alqahtani, F.A.; Qaddah, A. Delineating flood hazards using the interpreted structural setting and GIS in Attaif, western Saudi Arabia. Arab. J. Geosci. 2020, 13, 230. [CrossRef]

38. Amaro-Mellado, J.L.; Melgar-García, L.; Rubio-Escudero, C.; Gutiérrez-Avilés, D. Generating a seismogenic source zone model for the Pyrenees: A GIS-assisted triclustering approach. Comput. Geosci. 2021, 150, 104736. [CrossRef]

39. Tao, S.; Ying, X.; Yu, X.; Liu, W.; Wang, Y. Structural Controls on Copper Mineralization in the Tongling Ore District, Eastern China Evidence from Spatial Analysis. Minerals 2018, 8, 254.

40. He, H.; Hu, D.; Lü, G.; Li, A.; Li, J. GIS Data Modeling of a Regional Geological Structure by Integrating Geometric and Semantic Expressions. Acta Geod. Cartogr. Sin. 2017, 46, 1058-1068.

41. Zhang, Z.; Yi, R.; Ming, Y. 3D Complex Geological Modeling of Slope and Its Stability Analysis. Highw. Eng. 2014, $39,34-37$. (In Chinese)

42. Minnick, K.; Mattson, E.; Geza, M.; Zhou, D. GIS-based geospatial infrastructure of water resource assessment for supporting oil shale development in Piceance Basin of Northwestern Colorado. Comput. Geosci. 2015, 77, 44-53.

43. Li, N.; Bagas, L.; Li, X.; Xiao, K.; Li, Y.; Ying, L.; Song, X. An improved buffer analysis technique for model-based 3D mineral potential mapping and its application. Ore Geol. Rev. 2016, 76, 96-107. [CrossRef]

44. Jin, Y.; Su, D. Research on TIN-based 3D Geological Modeling. Comput. Eng. 2012, 7, 279-280.

45. Wang, Z.; Qu, H.; Wu, Z.; Yang, H.; Du, Q. Formal representation of 3D structural geological models. Comput. Geosci. 2016, 90, 10-23. [CrossRef]

46. Hina, S.; Kawasaki, A.; Qasim, M. Landslide Susceptibility Analysis Using GIS and Logistic Regression Model A Case Study in Malang, Indonesia. Anal. Math. 2014, 6, 117-129. [CrossRef] 
47. Lin, Y.; Wang, S.; Thiagarajan, J.; Guthrie, G.; Coblentz, D. Efficient Data-Driven Geologic Feature Detection from Pre-stack Seismic Measurements using Randomized Machine-Learning Algorithm. Geophys. J. Int. 2017, 215, 1900-1903.

48. Fan, R.; Wang, L.; Yan, J.; Song, W.; Chen, X. Deep Learning-Based Named Entity Recognition and Knowledge Graph Construction for Geological Hazards. Int. J. Geo-Inf. 2020, 9, 15. [CrossRef]

49. Kang, B.; Lee, K. Managing Uncertainty in Geological Scenarios Using Machine Learning-Based Classification Model on Production Data. Geofluids 2020, 2020, 8892556. [CrossRef]

50. Shao, H.; Sun, X.; Lin, Y.; Xian, W.; Qi, J. A method for spatio-temporal process assessment of eco-geological environmental security in mining areas using catastrophe theory and projection pursuit model. Prog. Phys. Geogr. 2021, 1, 647-668. [CrossRef]

51. Hughes, A.L.C.; Gyllencreutz, R.; Lohne, Ø.S.; Mangerud, J. The last Eurasian ice sheets-A chronological database and time-slice reconstruction, DATED-1. Boreas 2016, 45, 1-45. [CrossRef]

52. Roelofse, C.; Alves, T.M.; Gafeira, J.; Omosanya, K.O. An integrated geological and GIS-based method to assess caprock risk in mature basins proposed for carbon capture and storage. Int. J. Greenh. Gas Control 2019, 80, 103-122. [CrossRef]

53. Gürbüz, A.; Hakyemez, H.Y.; Leroy, S.; Roberts, N.; Saraç, G.; Ergun, Z.; Boyraz-Arslan, S.; Gürbüz, E.; Koc, K.; Yedek, Ö.; et al. Geological evolution of a tectonic and climatic transition zone: The Beyehir-Sula basin, lake district of Turkey. Int. J. Earth Sci. 2021, 110, 1077-1107. [CrossRef]

54. Porwal, A.; Carranza, E. Introduction to the Special Issue: GIS-based mineral potential modelling and geological data analyses for mineral exploration. Ore Geol. Rev. 2015, 71, 477-483. [CrossRef]

55. He, H.; Hu, D.; Lü, G. GIS Application to Regional Geological Structure Relationship Modelling Considering Semantics. ISPRS Int. J. Geo-Inf. 2018, 7, 267. [CrossRef]

56. Lin, F.; Guo, J.; Song, H.C. Management and service of distributed multi source heterogrnrous marine geological data. Mar. Geol. Front. 2018, 34, 21-25.

57. Guo, J.; Li, Y.; Jessell, M.W.; Giraud, J.; Liu, S. 3D geological structure inversion from Noddy-generated magnetic data using deep learning methods. Comput. Geosci. 2021, 149, 104701. [CrossRef]

58. Shi, M.; Wu, Z.; Wang, S.; Zhu, D. Real-time switching and visualization of logging attributes based on subspace learning. Comput. Geosci. 2020, 146, 104624. [CrossRef]

59. Pan, D.; Xu, Z.; Lu, X.; Zhou, L.; Li, H. 3D scene and geological modeling using integrated multi-source spatial data: Methodology, challenges, and suggestions. Tunn. Undergr. Space Technol. 2020, 100, 103393. [CrossRef]

60. Lyu, M.; Ren, B.; Wu, B.; Tong, D.; Ge, S.; Han, S. A parametric 3D geological modeling method considering stratigraphic interface topology optimization and coding expert knowledge. Eng. Geol. 2021, 293, 106300. [CrossRef]

61. International Chronostratigratigraphic Chart. Available online: http://www.stratigraphy.org/ICSchart/ChronostratChart2021-10.pdf (accessed on 1 October 2021). 